\title{
Earthquake and Seismogenic Fault, and What is the Active Fault
}

\author{
-Eliminate a Delusion and Rumor for Active Fault and \\ Give a Calm Response-
}

Tokyo Metropolitan University, Haruo Yamazaki

\begin{abstract}
In an investigation of the Tachikawa Fault, which is a major active fault in the western suburbs of Tokyo, an artificial object was mistaken for a fault fracture zone. This commentary discusses the cause of this error and points out that misunderstandings and incorrect assumptions must have been made regarding matters such as the patterns of surface ruptures that appear during a major earthquake. To avoid such misunderstandings, the commentary explains surface ruptures and active faults as consequences of their repetition. The prevention of disasters arising from active faults, which can trigger major earthquakes, would require us to predict the behavior of surface ruptures, which is prone to misunderstandings and incorrect assumptions due to insufficient knowledge and other factors. The dangers of such misunderstandings must be kept in mind to ensure that active faults and other hazards are dealt with calmly.
\end{abstract}

\section{Incorrect Assumptions in an Investigation of an Active Fault}

In its trench excavation investigation on the Tachikawa Fault, which is an active fault in the western suburbs of Tokyo, the Earthquake Research Institute (ERI) of the University of Tokyo mistook an artificial object that was probably made of cement for a fault fracture zone, which is usually formed by rocks being ground in repeated fault slips. In February 2013, the ERI provided a misleading explanation to nearly 10,000 citizens and the press when the site was displayed to the public. This incident had become big news by the end of March. The lead researcher for the investigation explained at a press conference that their incorrect assumptions had led them to mistake an artificial object for a fault fracture zone. This may well have been the case, but the issue that still needs to be addressed is how cement could have been mistaken for a fault fracture zone. The answer could be easily found in the documentary film "Megaquake," which was aired in an evening broadcast by NHK on April 7. The program showed a few people observing the supposed fault fracture zone in the exploratory trench. After that, a very brief narration announced that the site had been mistaken for a fault

DOI : 10.15669/fukushimainsights.Vol.2.173

(C) 2021 Atomic Energy Society of Japan. All rights reserved.

Originally published in Journal of the Atomic Energy Society of Japan (ISSN 1882-2606), Vol. 55, No. 6, p. 322-325 (2013)

in Japanese. (Japanese version accepted: April 17, 2013) 
before cutting to the next scene. However, a later explanation of a computer graphics (CG) of the fault activity there was astounding. This CG showed a surface rupture running like a bolt of lightning from a vast empty plot with a close resemblance to the site of the trench excavation investigation toward a city similar to Tachikawa that had a monorail. In the aired simulation, a vertical displacement emerged across roads in the city and the columns supporting the monorail collapsed. Apparently, the producer of the program had prepared the computer-generated simulation based on the survey findings explained by the ERI. When this explanation subsequently proved to be incorrect, the inconsistent part of the explanation was simply cut and the simulation was still aired. However, the incorrect assumption that led to this serious mistake was still there.

The Tachikawa Fault vertically displaces a vast alluvial fan that used to extend along the river banks of Tama River during the ice age that occurred about 20,000 years ago (the fan dried up to form the Tachikawa Terrace). This fan is composed of a thick (over $40 \mathrm{~m}$ ) poorly lithified gravel layer. A displacement involving a fault situated in deep lithified sandy and muddy sediments is dispersed in the thick gravel layer above them. The surface strata (gravel) are gently distorted without any slippage or vertical displacement. A gentle distortion with no discontinuity in the strata is called a "flexure." For this reason, there are no escarpments along the Tachikawa Fault. Instead, gentle slopes are ubiquitous. The first paper ${ }^{1)}$ that described the Tachikawa Fault has already mentioned flexure as its most striking feature.

In other words, fault movements underneath the Tachikawa Terrace do not produce the type of dramatic vertical surface displacement that was depicted in the CG simulation. Such fault movements will just cause the existing gentle slopes to steepen slightly from the flexure of the gravel layer. Lacking a proper understanding of this flexure, the ERI team conducted an investigation based on the incorrect assumption that any fault movement would result in clear slippage (vertical displacement). They then found a convenient vertical structure, which was prematurely deemed a fracture zone. Conventionally, scientific investigations of active faults have relied on the inductive inference of their presence based on various types of geological data. For the findings to be applied in disaster management and forecasting, the magnitude of earthquakes and the amount of displacement resulting from active faults would need to be inferred deductively based on available knowledge. In the process of doing this, even so-called experts are prone to make misguided assumptions or presumptions due to insufficient knowledge or misunderstandings in relation to fault movements. The failure of the many experts involved in this investigation to identify their mistake is most likely due to such incorrect assumptions and shared presumptions.

\section{Rumors about Active Faults}

News and media commentary on active faults are clearly misguided as they breed rumors that incite fear and an unreasonable aversion to such faults. The most critical misunderstanding with respect to active faults is that devastating fault displacements will necessarily cause the total destruction of nearby structures. People will naturally fear faults after seeing footage of buildings being destroyed along a displacement. However, our experience of earthquake disasters demonstrates that major damage, particularly casualties, is not caused primarily by collapsed structures as a direct result of fault displacements. On the contrary, most damage is caused by the impact of tsunamis, the collapse of buildings that lack seismic resistance and are situated on soft ground, and the spread of fire. If we incite fear of the displacement of 
active faults, we will blind ourselves to the real causes of damage and even exacerbate them. In Tachikawa and other parts of the Musashino Upland that are on solid ground, the truly formidable hazard that requires prudent measures is the spread of fire in areas with increasingly dense clusters of wooden dwellings.

To dispel misconceptions and rumors regarding active faults, the only solution is to provide ample explanations of earthquakes and active faults to interested parties so that they understand the actual process involved in identifying active faults. With this in mind, this commentary describes phenomena that occur on the ground surface due to fault movements with the aim of clarifying the relationship between earthquakes and active faults.

\section{Earthquakes and Faults}

Regardless of its magnitude, an earthquake is triggered underground by a fault movement; in other words, it is caused by the relative slippage and displacement of rock on either side of the fracture surface of a fault. Given the shallow crust of the Japanese Islands, faults in this country are driven by the strain that builds up inside the continental crust as an additional gain from plate movements and other factors. Within a certain range, this strain will accumulate along a fault as a weak line in the crust. When a concentration of stress overwhelms the frictional strength of the fault plane, the rock on one side of the fault plane slips relative to that on the other side. This displacement produces a strong seismic ground motion. A deep underground fault that triggers an earthquake is called a "seismogenic fault." In the inland part of the Japanese Islands, seismogenic fault movements occur only within a certain depth. Under the extremely high temperature that exists over $20 \mathrm{~km}$ beneath the Japanese Islands, the rock is too ductile to build up any strain. Furthermore, the rock situated about $3 \mathrm{~km}$ below the surface is too fragile to accumulate strain. For this reason, strain builds up and causes seismogenic fault movements in areas with hard rock within the range of 3 to $20 \mathrm{~km}$ underground. This part of the crust is called a "seismogenic layer."

There are many weak lines in a seismogenic layer, and fault movements in these layers are triggered in the most brittle parts according to the direction of stress and the strength of the fault planes. The amount of energy generated by an earthquake triggered by a fault slip is expressed in seismic moment (Mo; unit: N.m). There is a known relationship of Mo $=\mu \mathrm{AD}^{2)}$, wherein $\mu$ denotes the modulus of rigidity $(\mathrm{Pa}), \mathrm{D}$ represents the amount of displacement along the fault plane $(\mathrm{m})$, and A denotes the area of the fault $\left(\mathrm{m}^{2}\right)$. For intraplate earthquakes without a sizeable difference in $\mu$, the magnitude $(\mathrm{M})$ of an earthquake triggered by a fault depends on the area and displacement of the fault. The parameter A is a product of the horizontal length $\mathrm{L}$ of the fault and the width $\mathrm{W}$ along the depth direction. Since the thickness of a seismogenic layer is limited to about $17 \mathrm{~km}, \mathrm{M}$ depends on the fault length $\mathrm{L}$ and the displacement $\mathrm{D}$ as the fault grows bigger. In an earthquake with a high value for $\mathrm{M}$, the value grows in proportion to the fault length as the scaling law applies between D and L; in other words, a long fault is likely to cause an earthquake with a large magnitude. Figure 1 shows the relationship between the fault length and the magnitude in a cross section of the shallow continental crust of the Japanese archipelago. It also shows the magnitude at which a surface rupture emerges. An earthquake with a low value for $\mathrm{M}$ is triggered by a short seismogenic fault with a small displacement. The impact is felt only in the seismogenic layer without a visible fault slip appearing on the surface. In contrast, if the value for $\mathrm{M}$ is seven or greater, the seismogenic fault slips across the seismogenic layer and penetrates the upper boundary. A 


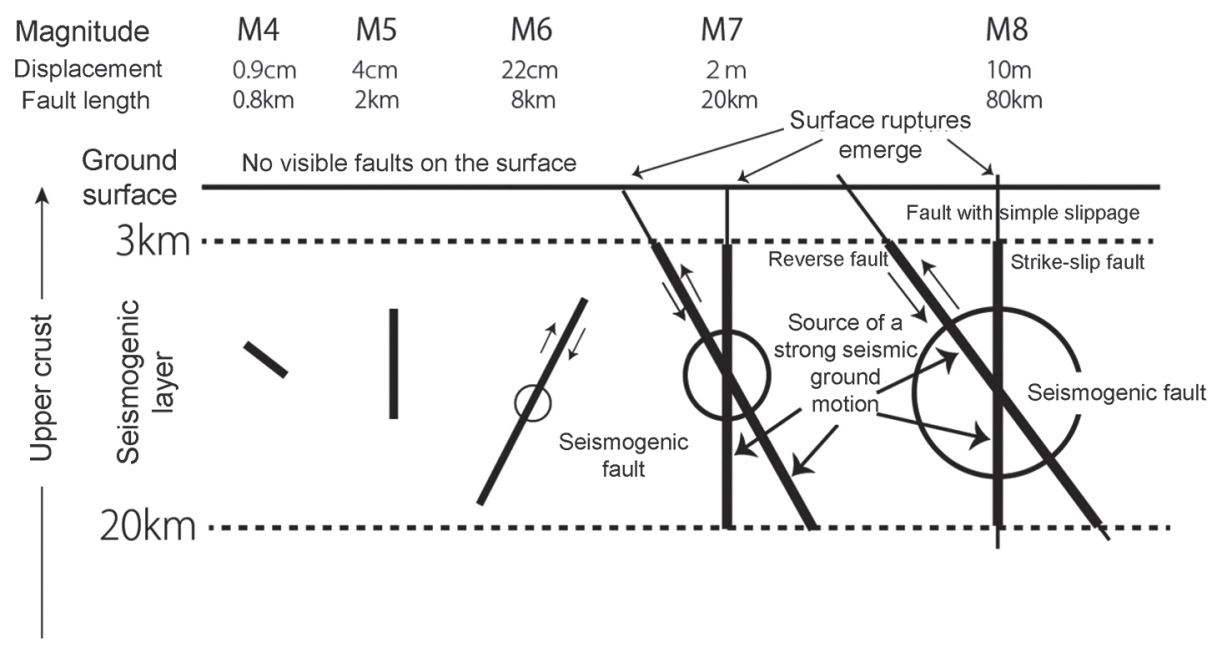

Figure 1 Relationship between a seismogenic layer and the presence of seismogenic faults and surface ruptures

fault that appears on the ground surface is called a "surface rupture."

Surface ruptures are an extension of seismogenic faults located under the ground surface. Their orientation and the amount of displacement are believed to provide important clues to understanding the nature of seismogenic faults located deep underground. Whenever faults appear due to a major earthquake, researchers record their details ${ }^{3,4}$. The faults that appear on the ground surface are not limited to master faults as a direct extension of the seismogenic faults. Spray faults also appear when a fault extends upward before branching out in a relatively brittle layer near the surface. A small secondary fault may appear if a fault that is not directly connected to a master fault slips as a result of a seismic ground motion or the like (Figure 2). Even if a detailed investigation is conducted after an earthquake, only master faults that exhibit a large displacement can be identified because it is difficult to distinguish smaller faults based on the source mechanism. Given this, unless they are clearly formed by the action of gravity on the surface, all faults are called surface ruptures with assumed structural origins. In other words, faults that appear on the ground surface are formed by many different factors.

Sometimes, secondary faults may appear on the ground surface due to ground consolidation, liquefaction, and landslides being induced by the tremors. Faults associated with landslides and the like are not classified as surface ruptures. As is the case with the Tachikawa Fault mentioned earlier, some conditions on the surface only result in flexural deformations or open cracks instead of visible master faults. For instance, the 1948 Fukui earthquake (M 7.1) was caused by a fault movement underneath a plane lying on thick alluvium. On the ground surface, only an extensive strip of irregular cracks was observed. However, a survey conducted after the earthquake confirmed that, within the range of a few kilometers, the ground had been displaced by $70 \mathrm{~cm}$ vertically and about $2 \mathrm{~m}$ horizontally ${ }^{5)}$. Most probably, the thick soft ground there led to invisible extensive flexure instead of ground ruptures. 


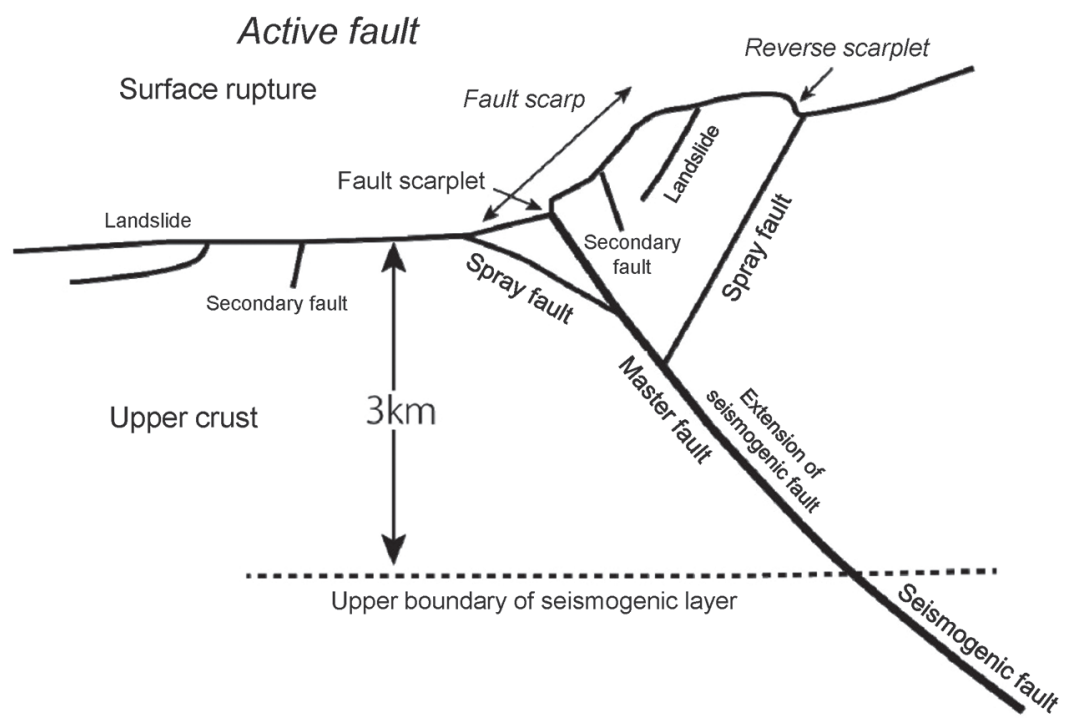

Figure 2 Various types of surface ruptures

Master faults shape the fault topography. There are also relatively large spray faults and small secondary faults. Some faults emerge due to landslides and other kinds of gravitational action on the surface.

\section{Repeated Surface Ruptures and Active Faults}

The huge movements of seismogenic faults that produce surface ruptures are believed to repeat in a cycle of over 1,000 years as they slowly accumulate strain during dormant periods before overwhelming the frictional strength to cause a fault displacement almost instantaneously (i.e., after a few dozen seconds). This belief is based on the concept that a fault will cause an earthquake of a similar magnitude at a constant interval provided no major changes occur in relation to the strain rate of the crust over time and the friction strength remains relatively stable.

Once surface ruptures emerge due to fault movements, they are eroded and buried by sedimentation. Small displacements and gaps tend to disappear over the long dormant period that follows. The scarplets of master faults and other faults with a sizeable displacement leave until their next period of activity. In the next period of activity, new slips are added to enlarge the land features and geological displacements. As a result, master faults gradually form large scarps or other distinctly discontinuous geological gaps. This type of distinct landscape that forms on the surface due to repeated fault movements is called "fault topography."

The Great Hanshin Earthquake that devastated Kobe in 1995 formed a surface rupture that extended about $10 \mathrm{~km}$ on the northwestern part of Awaji Island. This rupture forms part of the southwestern extension of the seismogenic fault from underneath the foot of Mt. Rokko, which is situated near Kobe City. This fault, known as the Nojima Fault, was active even before the earthquake. As indicated on the map shown in Figure 3 (a), the surface rupture emerged on Awaji Island along the northwest coast to form an upheaval on the eastern side of up to $1.2 \mathrm{~m}$ and a dextral strike-slip of up to $2.5 \mathrm{~m}$. This surface rupture runs straight along the foot of the steep slope that marks the northwestern border of Tsuna Hills on the northern part of the island (Figure 3 (b)). At the point where the rupture emerges, a fault fracture zone can be observed between the granite on the east side and the bordering Osaka Group on the 


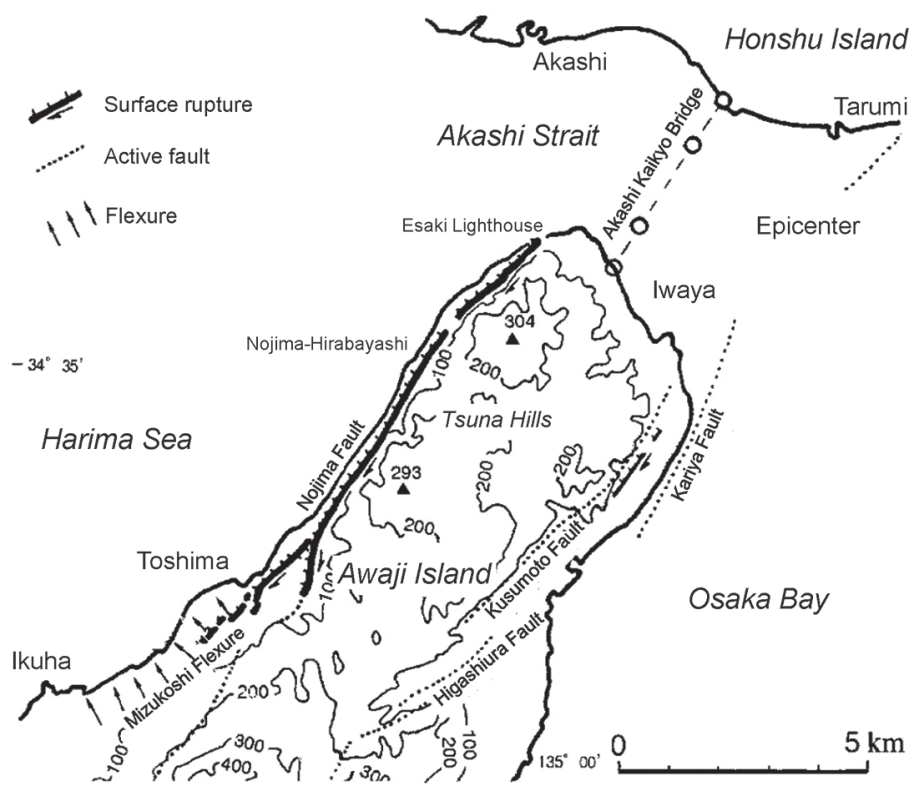

Figure 3 (a) Surface rupture that emerged along the northwestern coast of Awaji Island due to the Great Hanshin Earthquake in 1995

The Nojima Fault, which is known to have existed since before the earthquake, resumed its activity (Haruo Yamazaki, 1998) ${ }^{6)}$.

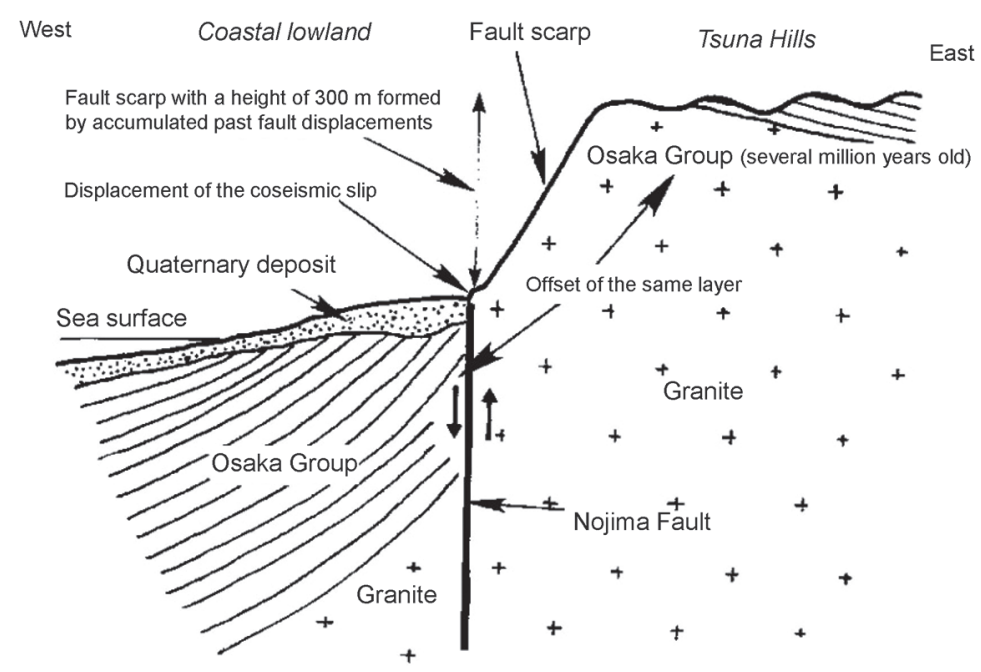

Figure 3 (b) East-west cross-section of the northern part of Awaji Island

The point at which the surface rupture emerged coincided with the foot of a large fault scarp.

west side. This zone indicates that the earthquake was generated by the resumed activity of a fault with a long history. On top of Tsuna Hills, which is formed of granite and located on the east side, the Osaka Group extends just as it does on the west side. The difference in height between these two sides amounts to $500 \mathrm{~m}$. This difference is a result of repeated fault activities in the geological period after the Pliocene. The steep slope that runs along the rupture was probably formed by fault movements. Put another way, faults that have formed fault 
scarps and the like due to their repeated activity in recent geological times are likely to continue to exhibit the same activity unless they experience any dramatic changes. Faults that may cause major earthquakes in any future activity were named "active faults" by Fumio $\mathrm{Tada}^{7)}$. In other words, faults that are geologically proven to have exhibited repeated activity in recent geological periods to form fault topography can be considered active faults with the potential to trigger major earthquakes in any future activity.

Worryingly, the recent use of terms such as "surface ruptures" and "active faults" seems to be increasingly diverging from the original concepts as explained in this commentary. As an example, let's consider the earthquake with an intensity of 6 lower on the Japanese scale (M 6.3) that struck Awaji Island early in the morning on April 13, 2013. The press repeatedly stated, "An unknown active fault has moved." Active faults are, by definition, visible on the ground surface. Around the epicenter of this particular earthquake, no active faults have been identified. Furthermore, none of the area's geological features or structures have the potential to be active faults. The earthquake had a high magnitude, but the displacement was limited to within the seismogenic layer. This displacement failed to reach the surface during this earthquake or any preceding ones. The media coverage confused a seismogenic fault with an active fault. The fault slips from small earthquakes that take place every day remain within the seismogenic layer. They are movements of completely unknown faults. The misguided association of such earthquakes with active faults may come from a subconscious desire to attract attention to the news by capitalizing on the current talk that "active faults are dangerous."

As this demonstrates, terms such as "active faults" and "surface ruptures" are frequently used in a way that is inconsistent with their original definitions or as idiomatic expressions. Having become mixed up with misunderstandings and misguided assumptions, these terms could breed or spread confusing rumors. We hope that this commentary will help dispel such rumors and facilitate a calm response to the hazards posed by active faults and surface ruptures.

\section{References}

1) H. Yamazaki: Tachikawa Fault and Its Movements in the Late Quaternary [in Japanese], Quaternary Research, 16, 231-246, 1978.

2) T. Utsu (editor-in-chief), E. Shima, T. Yoshii, and K. Yamashina (editors): Encyclopedia of Earthquakes [in Japanese], Asakura Publishing, 220, 1987.

3) T. Matsuda: Seismic Fault of the 1891 Nobi Earthquake [in Japanese], Earthquake Research Institute Preliminary Report, 13, 85-126, 1974.

4) H. Yamazaki, H. Koide, and E. Tsukuda: The Fault That Emerged During the 1978 Near Izu-Oshima Earthquake [in Japanese], Special Report by the Geological Survey of Japan, 7, 7-35, 1979.

5) H. Tsuya, ed.: The Fukui Earthquake of June 28, 1948, Report of the Special Committee for the Study of the Fukui Earthquake, 197, 1950.

6) H. Yamazaki: Active Faults and Seismic Disaster Management [in Japanese], The Memoirs of the Geological Society of Japan entitled "Earthquake and Geological Hazards-The 1995 Hyogo-Ken Nanbu Earthquake," 51, 135-143, 1998.

7) F. Tada: Two Types of Active Faults [in Japanese], Geographical Review of Japan, 3, 980-983, 1927. 